\title{
El concepto de identidad
}

\section{Cultura}

\section{RESUMO}

Neste artigo 0 autor trata do conceito de identidade em relação ao conceito simbólico de cultura.

\section{ABSTRACT \\ In this paper, the author discusses the concept of identity in relation to the symbolic concept of culture.}

\section{PALAVRAS-CHAVE (KEY WORDS) \\ - Identidade (Identity) \\ - Culture (Culture) \\ - América Latina (Latin America)}

Jorge Larrain*

Alberto Hurtado/Chile
INTENTARÉ ACLARAR EL CONCEPTO de identidad poniéndolo en relación con un concepto simbólico de cultura. El concepto de cultura, tal como lo usamos hoy, es históricamente hablando de reciente data y está asociado al nacimiento de la modernidad. Antes de ella se entendía por cultura el cuidado y crecimiento de las cosechas y animales y, por analogía, el cultivo y desarrollo de la mente, el perfeccionamiento de las facultades humanas. ${ }^{1}$ La ilustración empezó a agregarle nuevos significados. Así aparece el término "civilizar" como la adquisición de refinamiento y orden en oposición a la barbarie y al oscurantismo. Hasta fines del siglo XVIII cultura y civilización eran practicamente términos intercambiables. Después su sentido se separa: la cultura adquiere una connotación positiva mientras civilización una connotación negativa. A esto contribuyen varias corrientes de pensamiento.

Civilización es atacada por Rousseau y los románticos como lo artificial y superficial, el cultivo de propiedades externas como la buena educación y el refinamiento, en contradistinción con las necesidades interiores espirituales $y$ los impulsos humanos. De aquí nace un sentido del término cultura que la asocia con la religión, el arte, la familia y la vida personal, los significados y los valores, en general la vida interior. ${ }^{2}$ A medida que la religión va perdiendo posiciones en el proceso de secularización, cultura se transforma entonces en liberación de formas metafísicas y religiosas y es reemplazada por la estética: el arte y la literatura llegan a ser la expresión más profunda del espíritu humano.

Esta separación entre civilización y cultura es especialmente notable en la lengua alemana, donde, en parte 
condicionada por la visión de la nueva clase burguesa que se opone a la aristocracia feudal, la civilización pasa a ser lo propio de la nobleza y aparece como lo artificial y superficial, el cultivo de propiedades externas como las buenas maneras y el refinamiento y, la cultura, por el contrario, pasa a ser lo propio de los intelectuales y se refiere a las necesidades interiores espirituales, a los productos intelectuales y artísticos donde se expresa la creatividad humana. Kant, decía "llegamos a ser cultivados a través del arte y la ciencia, llegamos a ser civilizados adquiriendo una variedad de gracias sociales y refinamientos."3

A comienzos del siglo XIX el término cultura se utilizó también en el contexto de intentos por escribir historias universales del desarrollo de la humanidad. Así Herder hablaba de "culturas" en plural, para expresar la idea de que los procesos de desarrollo de cada pueblo contribuyen a la creación de distintas formas intelectuales o culturas diferentes. Todo este desarrollo configura lo que podríamos llamar la concepción clásica de cultura que se refiere a un proceso de desarrollo de facultades humanas relacionado con la asimilación de obras intelectuales y artísticas y vinculado al carácter progresista de la edad moderna. ${ }^{4}$

Hacia fines del siglo XIX se produce un cambio importante en el concepto, que se relaciona con el surgimiento de la antropología y que le da un carácter social. El énfasis en el desarrollo del espíritu se desplaza hacia un énfasis en las costumbres, prácticas, modos de vida y creencias de una sociedad. De algún modo este desplazamiento está condicionado por la expansión colonial europea y la necesidad de adaptar el concepto a las tareas de la descripción etnográfica de las colonias. Surge así un concepto antropológico-descriptivo de cultura, que consiste en el conjunto interrelacionado de creencias, costumbres, leyes, formas de conocimiento y arte, como también de artefactos materiales, objetos e instrumentos que pertenecen a los miembros de una sociedad y que los distinguen de otras sociedades. ${ }^{5}$ Tenemos así dos sentidos básicos del concepto de cultura que han permanecido en una relación inestable y de tensión. Por un lado cultura como arte y vida intelectual y por otro cultura como los significados y valores sedimentados en modos de vida diferentes y específicos. Esta distinción es importante, vamos a ver, para la comprensión de la identidad.

Pero, como John Thompson ha destacado 6 , a mediados del siglo $\mathrm{XX}$, bajo la influencia de nuevas tendencias antropológicas y linguísticas, se empezó a constituir una concepción simbólica de la cultura que destaca el uso de símbolos como un rasgo distintivo de la vida humana: los seres humanos crean e intercambian expresiones significativas (es decir, con sentido) no sólo mediante el lenguaje sino que también a través de objetos materiales, obras de arte y acciones a los que dotan de sentido. En esta perspectiva simbólica, la cultura vendría a ser el patrón de significados incorporados en formas simbólicas, incluyendo allí expresiones linguísticas, acciones y objetos significativos, a través de los cuales los individuos se comunican y comparten experiencias. Esta concepción simbólica de la cultura, al hacer del análisis cultural un estudio de la producción, trasmisión y recepción de formas simbólicas dentro de ciertos contextos socio-históricos, es especialmente adecuada para entender las relaciones existentes entre cultura e identidad, porque la identidad sólo puede construirse en la interacción simbólica con los otros.

\section{Identidad}

Cuando hablamos de identidad nos referimos, no a una especie de alma o esencia con la que nacemos, no a un 
conjunto de disposiciones internas que permanecen fundamentalmente iguales durante toda la vida, independientemente del medio social donde la persona se encuentre, sino que a un proceso de construcción en la que los individuos se van definiendo a sí mismos en estrecha interacción simbólica con otras personas. ${ }^{7}$ A través de la habilidad del individuo para internalizar las actitudes y expectativas de los otros, su sí mismo se convierte en el objeto de su propia reflexión. Esta relación reflexiva del sí mismo con el sí mismo debe ser entendida como hablarse a sí mismo, y hablarse a sí mismo debe entenderse como la internalización del habla comunicativa con los otros. El individuo se experimenta a sí mismo no directamente sino indirectamente; se hace objeto de sí mismo sólo al tomar las actitudes de otros individuos hacia él. ${ }^{8}$ La identidad, por lo tanto, es la capacidad de considerarse a uno mismo como objeto y en ese proceso ir construyendo una narrativa sobre sí mismo. Pero esta capacidad sólo se adquiere en un proceso de relaciones sociales mediadas por los símbolos. La identidad es un proyecto simbólico que el individuo va construyendo. Los materiales simbólicos con los cuales se construye ese proyecto son adquiridos en la interacción con otros.

Para Mead los individuos interactuan mediante gestos significantes, símbolos linguísticos que tienen un contenido que es más o menos el mismo para individuos diferentes y por lo tanto significan la misma cosa para todos ellos. Los gestos vocales, despiertan en el individuo mismo la respuestas que él está tratando de producir en el otro, de manera que desde el punto de vista de esa respuesta él es capaz de dirigir su conducta posterior. Los gestos significantes que envuelven el uso de símbolos siempre presuponen la habilidad de cada participante en un proceso comunicativo para visualizar su propio desempeño desde el punto de vista de los otros, para asumir el rol de los otros. ${ }^{9}$

La relación entre cultura e identidad es entonces muy estrecha en cuanto ambas son construcciones simbólicas, pero no son la misma cosa. Mientras la cultura es una estructura de significados incorporados en formas simbólicas a través de los cuales los individuos se comunican, la identidad es un discurso o narrativa sobre sí mismo construido en la interacción con otros mediante ese patrón de significados culturales. Mientras estudiar la cultura es estudiar las formas simbólicas, estudiar la identidad es estudiar la manera en que las formas simbólicas son mobilizadas en la interacción para la construcción de una auto-imagen, de una narrativa personal.

La construcción de identidad es así un proceso al mismo tiempo cultural, material y social. Cultural, porque los individuos se definen a si mismos en términos de ciertas categorías compartidas, cuyo significado está culturalmente definido, tales como religión, género, clase, profesión, etnia, sexualidad, nacionalidad que contribuyen a especificar al sujeto y su sentido de identidad. Estas categorías podríamos llamarlas identidades culturales 0 colectivas. Es material en cuanto los seres humanos proyectan simbólicamente su sí mismo, sus propias cualidades en cosas materiales, partiendo por su propio cuerpo; se ven a sí mismos en ellas y las ven de acuerdo a su propia imagen. Es también un proceso social, porque la identidad implica una referencia a los "otros" en dos sentidos. Primero, los otros son aquellos cuyas opiniones acerca de nosotros internalizamos, cuyas expectativas se transforman en nuestras propias autoexpectativas. Pero también son aquellos con respecto a los cuales queremos diferenciarnos. Podríamos entonces hablar de 3 elementos componentes de toda identidad: categorías colectivas, posesiones y los "otros"

El primer elemento hace alusión al hecho que toda definición identitaria requiere una referencia a categorías colectivas más generales que la especifican. Es imposible una autodefinición en términos 
de categorías únicas no compartidas por otros. Cuando a alguien le piden que diga quién es, su relato va a utilizar categorías compartidas con otros tales como religión, clase social, nacionalidad, género, etnia, orientación sexual, profesión, etc. Cada una de ellas puede considerarse como una identidad cultural o colectiva. Pero esto no sólo se aplica a identidades individuales sino también a identidades colectivas. Por ejemplo, en la definición identitaria de un país se utilizan también categorías más generales tales como: islámico/cristiano, norte/sur, hispánico/ anglosajón, desarrollado/subdesarrollado, europeo/latinoamericano, centro/periferia, oriente/occidente, etc. Esto significa que toda identidad requiere una referencia a un grupo más amplio con el que se comparten ciertas características.

El elemento material está muy bien descrito en la idea original de William James donde incluye el cuerpo y otras posesiones capaces de entregar al sujeto elementos vitales de auto-reconocimiento. En sus propias palabras:

Es claro que entre lo que un hombre llama mí y lo que simplemente llama mío la línea divisoria es difícil de trazar... En el sentido más amplio posible... el sí mismo de un hombre es la suma total de todo lo que él puede llamar suyo, no sólo su cuerpo y sus poderes psíquicos, sino sus ropas y su casa, su mujer y sus niños, sus ancestros y amigos, su reputación y trabajos, su tierra y sus caballos, su yate y su cuenta bancaria. ${ }^{10}$

La idea es que al producir, poseer, adquirir or modelar cosas materiales los seres humanos proyectan su sí mismo, sus propias cualidades en ellas, se ven a sí mismos en ellas y las ven de acuerdo a su propia imagen. Como lo decía Simmel,

Toda propiedad significa una extensión de la personalidad; mi propiedad es lo que obedece a mi voluntad, es decir, aquello en lo cual mi sí mismo se expresa y se realiza externamente. $Y$ esto ocurre antes y más completamente que con ninguna otra cosa, con nuestro propio cuerpo, el cual, por esta razón constituye nuestra primera e indis-cutible propiedad. ${ }^{11}$

Si esto es así, entonces los objetos pueden influenciar la personalidad humana. Es a través de este aspecto material que la identidad puede relacionarse con el consumo y con las industrias tradicionales y culturales. Tales industrias producen mercancías, bienes de consumo que la gente adquiere en el mercado, sean objetos materiales o formas de entretención y arte. Cada compra o consumo de estas mercancías es tanto un acto por medio del cual la gente satisface necesidades como un acto cultural en la medida que constituye una manera culturalmente determinada de comprar o de consumir mercancías. Así por ejemplo, yo puedo comprar una entrada para ir a la ópera porque con la ópera experimento un placer estético. Pero también puedo comprar una entrada para la ópera, que no me gusta mucho, para ser visto en compañía de cierta gente que yo estimo importante o de alto status. Puedo comprar un auto especial porque me gusta es estéticamentes y necesito movilidad, pero también puedo comprarlo para ser visto como perteneciente a un cierto grupo o círculo particular que es identificable por el uso de esa clase de auto.

En otras palabras, el acceso a ciertos bienes materiales, el consumo de ciertas mercancías, puede también llegar a ser un medio de acceso a un grupo imaginado representado por esos bienes; puede llegar a ser una manera de obtener reconocimiento. Las cosas materiales hacen pertenecer o dan el sentido de pertenencia en una comunidad deseada. En esta medida ellas contribuyen a modelar las identidades personales al simbolizar una identidad colectiva o cultural a la cual 
se quiere acceder.

En tercer lugar, la construcción del sí mismo necesariamente supone la existencia de "otros" en el doble sentido ya advertido de otros significativos y otros de diferenciación. Los primeros son aquellos cuyas opiniones acerca de nosotros internalizamos. Como dicen Gerth y Mills, "nuestra auto-imagen total implica nuestras relaciones con otras personas y su evaluación de nosotros." ${ }^{2}$ El sujeto internaliza las expectativas o actitudes de los otros acerca de él o ella, y estas expectativas de los otros se transforman en sus propias auto-expectativas. El sujeto se define en términos de como lo ven los otros. Sin embargo, sólo las evaluaciones de aquellos otros que son de algún modo significativos para el sujeto cuentan verdaderamente para la construccción y mantención de su auto-imagen. Los padres son al comienzo los otros más significativos, pero más tarde una gran variedad de "otros" empiezan a operar (amigos, parientes, pares, profesores, etc.).

Mead sostenía que en la relación con cada uno de estos "otros" se forma en una persona una variedad de sí mismos elementales ("somos una cosa para un hombre y otra cosa para otro"), pero que si se consideran los otros significativos en conjunto, se puede ver que se organizan en un "otro generalizado" en relación con el cual se forma un "sí mismo completo". ${ }^{13}$ El otro generalizado, por lo tanto, está compuesto por la integración de las evaluaciones y expectativas de los otros significativos de una persona. ${ }^{14}$ De este modo la identidad socialmente construida de una persona, por ser fruto de una gran cantidad de relaciones sociales, es inmensamente compleja y variable, pero al mismo tiempo se supone capaz de integrar la multiplicidad de expectativas en un sí mismo total coherente y consistente en sus actividades y tendencias.

Por lo tanto, la identidad en un sentido personal es algo que el individuo le presenta a los otros y que los otros le presentan a él. La identidad supone la existencia del grupo humano. Responde no tanto a la pregunta ¿quién soy yo? o "¿qué quisiera ser yo?" como a la pregunta: "¿quién soy yo a los ojos de los otros?" o "¿qué me gustaría ser considerando el juicio que los otros significativos tienen de mi?" Erikson expresa esta idea diciendo que en el proceso de identificación "el individuo se juzga a sí mismo a la luz de lo que percibe como la manera en que los otros lo juzgan a él." ${ }^{15}$ El medio social no sólo nos rodea, sino que también está dentro de nosotros. En este sentido se podría decir que las identidades vienen de afuera en la medida que son la manera como los otros nos reconocen, pero vienen de adentro en la medida que nuestro auto-reconocimiento es una función del reconocimiento de los otros que hemos internalizado.

Pero la identidad no es puramente una construcción pasiva constituída por las expectativas de los otros, es un proceso de interacción por medio del cual la identidad del sujeto es construída no sólo como una expresión del reconocimiento libre de los otros, sino también como resultado de una lucha por ser reconocido por los otros. En otras palabras, como lo ha sugerido Honneth, la construcción de la identidad es un proceso intersubjetivo de reconocimiento mutuo. ${ }^{16}$ La distinción entre el "mí" y el "yo" sugerida por Mead puede usarse para sustentar la idea de una lucha por el reconocimiento. Para Mead el "mí" era el conjunto organizado de actitudes de los otros. El "yo" era la respuesta o reacción del individuo a las actitudes de los otros. ${ }^{17}$ Mientras el "mí" refleja las expectativas e imágenes que los otros tienen del sujeto, el "yo" busca activamente ser reconocido por los otros.

Honneth arguye que una identidad bien integrada depende de tres formas de reconocimiento: amor o preocupación por la persona (que da auto-confianza), respeto a sus derechos (que entrega auto-respeto) y aprecio por su contribución (que garantiza auto-estima). Cuando estas formas de 
reconocimiento son denegadas, el "yo" tiene una reacción emocional negativa (rabia, indignación) que, de acuerdo a Honneth, es la base motivacional de la lucha por el reconocimiento. ${ }^{18} \mathrm{La}$ experiencia de la falta de respeto en estos tres órdenes sería la fuente de las formas colectivas de resistencia y lucha social. Pero éstas no son un resultado automático de respuestas emocionales individuales. Sólo si existen los medios de articulación intersubjetiva de tales emociones en un movimiento social, nacerán formas colectivas de lucha. La búsqueda de reconocimiento personal puede también manifestarse como una proyección personal en los objetos de consumo, que se han convertido en símbolos de la comunidad imaginada a la que uno quiere pertenecer o por la cual uno quiere ser respetado. En contraste con la lucha colectiva por el reconocimiento, la lucha por el reconocimiento basada en el consumo es altamente individualizada y atomizada.

La identidad también presupone la existencia de otros que tienen modos de vida, valores, costumbres e ideas diferentes. Para definirse a si mismo se acentuan las diferencias con los otros. La definición del sí mismo siempre envuelve una distinción con los valores, características y modos de vida de otros. En la construcción de cualquier versión de identidad la comparación con el "otro" y la utilización de mecanismos de diferenciación con el "otro" juegan un papel fundamental: algunos grupos, modos de vida o ideas se presentan como fuera de la comunidad. Así surge la idea del "nosotros" en cuanto distinto a "ellos" o a los "otros". A veces, para definir lo que se considera propio se exageran las diferencias con los que están fuera y en estos casos el proceso de diferenciación se transforma en un proceso de abierta oposición y hostilidad al otro. Si bien la diferenciación es un proceso indispensable para la construcción de identidad, la oposición hostil al otro no lo es, y constituye un peligro de todo proceso identitario.

El proceso de identificación por oposición al otro ha existido siempre en la historia. Los griegos antiguos dividían el mundo entre los griegos y los bárbaros. Bárbaros eran aquellos que hablaban otras lenguas y no podían hablar griego, convirtiéndose así en los "otros" de la identidad griega. Sin embargo, como lo ha sostenido García-Gual, el principio de la diferencia de lenguaje muy pronto evolucionó hacia una forma de desprecio: aquellos que no hablaban griego fueron considerados atrasados, rudos, rebeldes e intelectualmente inferiores. La propia lengua griega facilitó esta transición de la diferencia al desprecio: la palabra logos tenía el doble significado de palabra hablada y razón, es decir, significaba tanto lenguaje inteligible como la realización del orden. De allí que el bárbaro que no podía hablar griego, también se exponía a ser juzgado como irracional o falto de orden y lógica. La lengua griega se había convertido así en el vehículo por excelencia de la razón. Por eso se puede comprender por qué Aristóteles, Eurípides e Isócrates justificaban la esclavitud como el resultado de la natural superioridad de los griegos y de la natural inferioridad de los bárbaros..$^{19}$

Hay evidencia de que estos mecanismos de identificación también existían entre los diversos pueblos indígenas de América precolombina. Las crónicas de Sahagún narran como los nahuas en América Central consideraban a los otomíes como tontos, perezosos y lascivos. Tanto así que entre los nahuas se acostumbraba a llamar otomí a alguien que no entendía. De igual forma consideraban a los huaxtecas como borrachos e impúdicos por andar sin taparrabos. Se daba allí también, como entre los griegos, la creencia que la lengua náhuatl era más refinada y sofisticada que las lenguas toscas e ininteligible de los pueblos vecinos. ${ }^{20}$ También hay numerosos ejemplos históricos de identificación en que la oposición se exagera hasta fomentar la exclusión en 
diversos grados: de marcar la diferencia se puede pasar a la desconfianza, de ésta a la abierta hostilidad y, de aquí, a la agresión y el exterminio. Esta es la lógica que terminó en el holocausto de los judíos y en los conflictos entre hutus y tutsis en Rwanda y entre musulmanes bosnios y serbios en la antigua Yugoeslavia.

\section{Identidades individuales y colectivas}

¿Cuál es la relación entre identidades personales y colectivas? Lo primero que hay que decir acerca de esta distinción es que las identidades personales y colectivas están interrelacionadas y se necesitan recíprocamente. No pueden haber identidades personales sin identidades colectivas y viceversa. Lo que significa que, aunque ciertamente hay una distinción analítica entre las dos, no pueden ser concebidas aparte y sustancializadas como entidades que pueden existir por sí sólas sin una referencia mutua. Esto es así porque las personas no pueden ser consideradas como entidades aisladas y opuestas a un mundo social concebido como una realidad externa. Los individuos se definen por sus relaciones sociales y la sociedad se reproduce y cambia a través de acciones individuales. Las identidades personales son formadas por identidades colectivas culturalmente definidas, pero éstas no pueden existir separadamente de los individuos.

Así por ejemplo, el ser chileno o brasilero nos hace pertenecer a un colectivo, nos hace parte de un grupo que puede ser identificado por algunos rasgos específicos. Pero en sí mismas, la chilenidad o brasilidad significan muy poco sin una referencia a personas individuales concretas que continuamente las recrean por medio de sus prácticas. Las identidades colectivas no deben ser hipostasiadas como si tuvieran una existencia independiente y pertenecieran a un individuo colectivo absolutamente integrado.
Esta mutua implicación no debe ocultar, sin embargo, las diferencias entre identidades individuales y colectivas. Estas diferencias son fundamentalmente dos y dicen relación, primero, con la naturaleza psicológica o meramente cultural de sus contenidos y segundo, con la mayor o menor pluralidad de los discursos identitarios que normalmente las expresan. La primera diferencia puede presentarse diciendo que mientras las identidades individuales tienen contenidos psicológicos, las identidades colectivas no pueden describirse en términos psicológicos. La segunda diferencia consiste en que mientras las identidades individuales normalmente tienen un sólo relato identitario más o menos integrado, las identidades colectivas normalmente poseen varios discursos identitarios. Veamos estas diferencias en orden.

\section{Identidad y estructura psíquica}

Si atendemos a la naturaleza de sus contenidos, hay que evitar trasponer los elementos psicológicos de las identidades personales a las identidades culturales. Mientras es posible y legítimo hablar de una identidad personal en términos del "carácter" o la "estructura psíquica" de un individuo, no es adecuado hablar de una identidad colectiva en términos de un "carácter étnico" o de una "estructura psíquica colectiva" que sería compartida por todos los miembros del grupo. Una identidad colectiva no tiene estructura psíquica o de carácter en el sentido de un número definido de rasgos psicológicos. No se puede decir que un carácter colectivo se manifiesta en el conjunto de carácteres individuales; por ejemplo, que los chilenos comparten una estructura de carácter chilena, que es diferente de la estructura de carácter brasilera. Existen diferencias culturales entre ambas naciones, que duda cabe, pero es muy improbable que existan diferencias significativas al nivel de rasgos psicológicos abstractos. 
En antropología, la escuela culturalista norteamericana que incluye a Margaret Mead, Ruth Benedict, Ralph Linton y Clyde Kluckhohn, entre otros, tendía a trabajar con esta idea de que los individuos de una sociedad particular tienen una estructura de carácter común, un patrón cultural, que puede ser descrito en términos de una serie de rasgos psicológicos. De este modo se podía hablar del "carácter nacional" o de la "mentalidad de un pueblo" o de la "personalidad básica" que consistía en una serie de características psicológicas, relativamente estables, compartidas por los miembros de una sociedad por el hecho de poseer la misma cultura. En un comienzo estos antropólogos estudiaron culturas primitivas mediante la observación participante en el terreno mismo, pero con posterioridad, ampliaron su campo de acción.

En efecto, durante la Segunda Guerra Mundial estos mismos autores encabezaron estudios de "cultura a distancia" para determinar los rasgos del carácter nacional de algunos pueblos extranjeros, que eran financiados por agencias gubernamentales con el objeto de establecer un posible modelo de conducta de naciones enemigas. ${ }^{21}$ Kluckhohn, por ejemplo, describía el carácter ruso como "caluroso y humano, tremendamente dependiente de afiliaciones sociales seguras, inestable, irracional, fuerte pero indisciplinado, necesitado, por lo tanto, de estar sometido a alguna clase de autoridad." 22 Del mismo modo Ruth Benedict estudió el carácter nacional japonés y otros se hicieron cargo de Polonia, China, Checoeslovaquia, etc. Pero la influencia de esta tendencia fue más allá de este objetivo estrecho inicial y en muchos otros países han florecido estudios acerca del carácter nacional como una manera de definir la identidad nacional.

América Latina no es una excepción y ha tenido su cuota de estudios del carácter nacional. Maritza Montero describe el carácter venezolano en términos de 3 rasgos positivos: igualitarismo, coraje y generosidad, y 7 rasgos negativos: flojera, pasividad, emotividad, autoritarismo, violencia, pesimismo y falta de sentido histórico. ${ }^{23}$ Leite hace lo mismo con los brasileros, que aparecen como indolentes, prejuiciados, ineptos para el trabajo, maliciosos, sensuales, dionisíacos. ${ }^{24} \mathrm{En}$ Chile, Francisco Antonio Encina propone en 1910 la idea de que "los pueblos, como los individuos, tienen temperamento y carácter propios, que imprimen un sello personal y exclusivo a todas las manifestaciones de su actividad. No existen dos razas que piensen, sientan y obren exactamente igual." 25 Basado en esto realiza su análisis del desastre moral y la inferioridad económica que resulta de tratar de educar demasiado intelectualmente al pueblo chileno. Más recientemente Hernán Godoy, Maria Elena Montt y Cristián Tolosa, se esfuerzan también por analizar los rasgos del carácter nacional chileno. Hernan Godoy, por ejemplo, concluye su descripción del carácter chileno destacando sobriedad, seriedad, prudencia, sentido de humor, gran temor al ridículo, pero también servilismo, crueldad, imprevisión, entre muchos otros rasgos. ${ }^{26}$

Estos listados de rasgos psicológicos supuestamente pertenecientes a un carácter nacional muestran por si mismos su inadecuación, en la medida que, claramente, no son compartidos por todos los miembros de esas sociedades. Sería aventurado aun decir que son compartidos por la mayoría de una nación. Constituyen sobregeneralizaciones abstractas que no pueden predicarse de toda una nación. Además, con tal grado de generalidad, es imposible establecer ninguna clase de discriminación real entre diferentes culturas. ¿Qué significa decir que el coraje es parte del carácter chileno, cuando lo mismo se afirma del carácter británico, del carácter norteamericano, del carácter alemán y así sucesivamente? Uno sospecha que, en circumstancias particulares y dadas algunas condiciones específicas, la gente de cualquier nación puede mostrar su coraje o 
debilidad. Optimismo, tristeza, sensibilidad, coraje, indolencia, sensualidad, etc., no pueden juzgarse características esenciales de la "estructura psíquica" de ningún pueblo. Es un error ontologizar para un colectivo, lo que son rasgos psicológicos individuales.

Fuera de las debilidades metodológicas que consisten en la transposición indebida de factores del orden psicológico individual al orden colectivo, estas posiciones tienen también peligros adicionales que dicen relación con la entrega de elementos que facilitan la construcción del "otro" por medio de estereotipos. Cuando se dice que "los indios son flojos", "los italianos son malos militares", "los argentinos son arrogantes", "los latinoamericanos son imprevisores", "los escoseses son tacaños", en el fondo se está haciendo la misma sobregeneralizació $\mathrm{n}$ indebida de atribuir un rasgo psicológico individual a todo un colectivo, pero además con la intención de mostrar la inadecuación o falencia de todo un pueblo o nación en oposición a lo que se considera la identidad propia. Desde mi punto de vista, por lo tanto, es un error reducir la identidad nacional al "carácter nacional".

En su contenido mismo, una identidad colectiva es puramente un artefacto cultural, un tipo de "comunidad imaginada" como lo establece Anderson en el caso de la nación. ${ }^{27}$ Pienso que lo que Anderson dice de la nación es también aplicable a otras identidades culturales tales como la sexualidad, la etnia, la clase social, el género, etc. En todos estos casos, los miembros de estas comunidades imaginadas son limitados en número, pero "nunca conocerán a la mayoría de sus compañeros miembros, ni estarán con ellos ni siquiera los oirán, sin embargo en la mente de cada uno de ellos vive la imagen de su comunión. ${ }^{28}$ Sin perjuicio de esto, es claro que no podemos igualar todas estas identidades culturales y que cada una de ellas tiene su propia historia y resonancia individual. Muchos millones han muerto o matado por sus naciones desde que empezó la modernidad. Hasta hoy, por el contrario, ser heterosexual no ha sido algo que haya inspirado un gran sentido de fraternidad, y ciertamente muy pocos han muerto o matado específicamente por eso. Ser mujer, homosexual o negro no ha supuesto, hasta ahora, tanta fraternidad imaginada como el hecho de ser brasilero o peruano, y sin embargo, ha ido crecientemente creando en muchos individuos grados de compromiso y lealtad personal que son mayores que los de los heterosexuales.

Esto significa que cada identidad cultural demanda una cantidad diferente de compromiso de cada miembro individual o supone un grado diferente de fraternidad imaginada, y que esto puede cambiar históricamente. Las identidades culturales no son estáticas. La clase social, la nacionalidad y la sexualidad casi no tenían presencia antes de que llegara la modernidad y por lo tanto no contaban en la construcción de identidades personales. Hoy día hay signos de que la clase social y la nacionalidad han empezado a declinar con la llegada de la modernidad tardía mientras las identidades de género, sexuales y étnicas se expanden. Por lo tanto, las identidades colectivas comienzan históricamente, se desarrollan y pueden declinar o desaparecer.

\section{Versiones públicas y privadas}

Pero hay una segunda diferencia entre identidades individuales y colectivas. Las primeras tienden a manifestarse en un sólo discurso más o menos integrado, salvo en casos de disociación o esquizofrenia. Es cierto que las tesis posmodernistas hablan del sujeto decentrado en los tiempos posmodernos. Pero esta tesis no tiene asidero en la realidad porque la gente sigue aspirando y logrando una cierta coherencia interior. Puede ser cierto que en la modernidad tardía el discurso 
identitario personal cambie y se modifique más aceleradamente que antes, pero eso no implica necesariamente la existencia simultanea de una pluralidad discursos. En cambio, las identidades colectivas normalmente se expresan en una variedad de discursos. Esto es especialmente cierto en el caso de las indentidades nacionales. Sin embargo, frecuentemente se comete el error de querer transferir indebidamente el carácter único del discurso identitario individual al caso de las identidades colectivas.

En efecto, la mayoría de los discursos identitarios nacionales, por analogía a la identidad individual, quieren hacernos creer que existe una versión única verdadera de la identidad nacional; que uno podría de algún modo determinar con precisión lo que pertenece a ella (y es más o menos compartida por todos en la sociedad) y lo que está fuera de ella. Pero la realidad es que el proceso discursivo de construcción de la identidad nacional es siempre un proceso de carácter altamente selectivo y excluyente, en el sentido que elige algunos rasgos considerados fundamentales y deja fuera a muchos otros. De allí que sea posible construir varias versiones sobre la identidad nacional que representan intereses, valores y grupos sociales distintos.

Cuando se analiza el carácter selectivo y excluyente de todo proceso de constitución de un discurso identitario nacional se puede ver que no hay nada natural o espontáneo en él y que varias otras versiones podrían igualmente ser (y de hecho son) construídas utilizando otras selecciones y exclusiones. La construcción de la identidad nacional no es un proceso monolítico y autónomo que ocurre con total independencia de la pluralidad de modos de vida, de la diversidad de prácticas sociales y de las múltiples divisiones sociales que existen en la sociedad. Aunque se plantee con pretensiones absolutas, toda construcción de identidad nacional es necesariamente limitada en su capacidad de representación de la diversidad cultural y social subyacente.

Además es importante advertir que la identidad nacional existe en dos polos distintos de la realidad socio-cultural. Por una parte, existe en la esfera pública como una variedad de discursos articulados altamente selectivos, construidos desde arriba por una variedad de instituciones y agentes culturales. Por otra parte, existe en la base social como una forma de subjetividad individual y de diversos grupos, que expresa sentimientos muy variados, a veces no bien representados en las versiones públicas. Estas últimas constituyen expresiones altamente articuladas y elaboradas de conciencia; las formas privadas, en cambio, tienen un carácter más implícito y contradictorio y son menos articuladas que los discursos públicos.

Es necesario destacar que la distinción entre las dimensiones públicas y privadas de la identidad nacional no significa que éstas sean dos mundos separados y sin relación. Las versiones públicas de identidad se construyen a partir de los modos de vida de la gente en la vida diaria, pero, a su vez, influyen sobre la manera como la gente se ve a sí misma y cómo actúa. Esta influencia no es automática o mecánica: muchos individuos, grupos étnicos, subculturas, regiones o sectores de la sociedad no se sienten bien representados por las versiones públicas y no comparten algunos rasgos de identidad o negocian una manera particular de entenderlos, o, simplemente, tienen una versión distinta. Richard Johnson ha representado este proceso complejo de construcción de la identidad nacional por un movimiento circular que supone cuatro momentos que parten de la base del círculo ${ }^{29}$ :

En la base existe una sociedad compleja con una cultura crecientemente diversificada y una gran variedad de modos de vida. De esta gran y compleja fuente, los intelectuales, dentro de 
instituciones culturales tales como los medios de comunicación, las iglesias, los aparatos educacionales e instituciones políticas, económicas y militares, producen algunas versiones públicas de identidad que seleccionan algunas características nacionales que se consideran representativas; excluyen otras. Estas versiones públicas, a su vez, influyen en la manera cómo la gente se ve a sí misma y como actúa, a través de un proceso activo más o menos crítico de lectura o recepción, cerrándose así el círculo. De este modo, las culturas locales y cotidianas constituyen tanto el comienzo como el fin del circuito. Las versiones públicas se construyen a partir de los modos de vida, pero también constituyen lugares de lucha que dan forma a la pluralidad de los modos de vida. Para esto, sin embargo, requieren de una relación efectiva con el sentido común de la gente, una capacidad para producir significados, símbolos e imágenes que cautiven el imaginario popular. ${ }^{30}$ Esta capacidad de dar forma a la vida cotidiana no es nunca simple y directa. Los individuos y grupos sociales transforman, rechazan, apropian y reinterpretan, activamente, tales discursos en su vida diaria.

He destacado el rol de las instituciones culturales en la construcción de diferentes versiones de la identidad nacional, pero, sin duda, el estado tiene un enorme peso en la articulación de los discursos de identidad nacional. Esto lo hace no sólo a través de sus propias instituciones educacionales y culturales, no sólo a través del discurso de las diversas instituciones estatales tales como el ejército y la variedad de los medios de comunicación que controla, sino también a través de la creación o provisión de muchos de los contenidos y símbolos de la identidad nacional: tradiciones, ceremonias, celebraciones, días nacionales, aniversarios, paradas militares, etc. El ceremonial del estado, la bandera, la canción nacional, los aniversarios nacionales son todos símbolos creados por el estado que buscan extender el sentido de una identidad común al unir y activar la comunidad imaginada que es la nación.

\section{Concepciones Teóricas sobre la Identidad Nacional}

Finalmente, no está demás distinguir 3 posiciones teóricas diferentes sobre la identidad nacional. Por un lado está el constructivismo, derivado del postestructuralismo, que destaca la capacidad de ciertos discursos para "construir" la nación, para interpelar a los individuos y constituirlos como "sujetos nacionales". El esencialismo, en el otro extremo, piensa la identidad cultural como un hecho acabado, como un conjunto ya establecido de experiencias comunes y de valores fundamentales compartidos que se constituyó en el pasado, como una esencia inmutable, de una vez para siempre. Al privilegiar el rol fundante de los discursos altamente coherentes y articulados, el constructivismo necesariamente concibe la identidad nacional como construida "desde arriba", en la esfera pública, y descuida las formas discursivas y prácticas populares y privadas. Al considerar la identidad como una esencia inmutable, el esencialismo descuida la historia y el hecho de que la identidad va cambiando. ${ }^{31}$

De allí que yo me ubico en la tercera concepción que denomino históricoestructural. La concepción históricoestructural desea establecer un equilibrio entre los dos extremos anteriores. Por una parte piensa la identidad cultural como algo que está en permanente construcción y reconstrucción dentro de nuevos contextos y situaciones históricas, como algo de lo cual nunca puede afirmarse que está finalmente resuelto o constituido definitivamente como un conjunto fijo de cualidades, valores y experiencias comunes. Por otra parte, no concibe la construcción de la identidad únicamente como un proceso discursivo público, sino que también considera las prácticas y 
significados sedimentados en la vida diaria de las personas. La concepción históricoestructural concibe la identidad como una interrelación dinámica del polo público y del polo privado, como dos momentos de un proceso de interacción recíproca.

Es importante subrayar que esta concepción, a diferencia del esencialismo, no solo mira al pasado como la reserva privilegiada donde están guardados los elementos principales de la identidad; también mira hacia el futuro y concibe la identidad como un proyecto. La pregunta por la identidad no sólo es entonces ¿qué somos?, sino también ¿qué queremos ser? Tal como Habermas argumenta, "la identidad no es algo ya dado, sino también, y simultáneamente, nuestro propio proyecto." 32 Esto hay que entenderlo tanto en el nivel del discurso público como en el nivel de las experiencias individuales y grupales. Es claro que cualquier proyecto articulado por un discurso específico no puede pretender el monopolio de la construcción de la identidad sin considerar las formas populares, los significados y las tradiciones decantadas en la vida diaria por prácticas de larga data. Pero también es cierto que en la construcción del futuro de acuerdo a un proyecto determinado todas las tradiciones históricas no valen del mismo modo. Habermas insiste en la profunda ambivalencia de las tradiciones nacionales: no todo lo que constituye una tradición nacional es necesariamente bueno y aceptable para el futuro. Si bien es cierto que una nación no puede elegir libremente sus tradiciones, puede, por lo menos, decidir políticamente si continuar o no continuar con algunas de ellas. ${ }^{33}$

Los países latinoamericanos no pueden eximirse de un análisis crítico profundo de sus propias tradiciones culturales y de la obligación de meditar sobre aquellas que podrían abandonarse y aquellas que sería bueno mantener. Esta es la precondición mínima para una apertura hacia otros países latinoamericanos, muchos de cuyos valores no deberían ser rechazados en aras de un nacionalismo estrecho. ${ }^{34}$ La propia y tan anhelada integración latinoamericana depende de esto .

Notas

* 0 autor é atualmente diretor do Departamento de Ciências Sociais da Universidade Alberto Hurtado, sediada em Santiago, Chile. Entre os diversos cargos que ocupou na carreira acadêmica foi diretor do Departamento de Estudos Culturais da Birmingham University (Inglaterra), no período de 1988-1993. Suas principais publicações: Identidad Chilena (Santiago: LOM ediciones, 2001); Identity and Modernity in Latin America (Cambridge: Polity Press, 2000); Modernidad, Razón e Identidad en América Latina (Santiago: Editorial Andrés Bello, 1996) - "Premio Municipal de Literatura 1997" no gênero Ensaio. Santiago, Chile.

1 Véase Raymond Wiliams, Marxism and Literature (Oxford: OUP, 1977), p. 13.

2 Ibid., p. 14.

3 Citado en J. Thompson, Ideology and Modern Culture (Cambridge: Polity Press, 1990), p. 125.

4 lbid., p. 126.

5 lbid., p. 128.

6 Ibid., pp. 130-145.

7 Véase sobre esto George Mead, Mind, Self and Society (Chicago: University of Chicago Press, 1974), pp. 1 \& 135

8 Ibid., p. 138.

9 Ibid., pp. 146-7.

10 William James, The Principles of Psychology, (London: Macmillan, 1890), Vol. I, p. 291.

11 Georg Simmel, Sociología (Madrid: Espasa Calpe, 1939), p. 363.

12 H. Gerth and C. Wright Mills, Character and Social 
Structure (New York: Harbinger Books, 1964), p. 80.

13 G.H. Mead, Mind, Self, \& Society, p. 142 -144.

$14 \mathrm{H}$. Gerth and C. Wright Mills, Character and Social Structure, p. 95.

15 E. Erikson, Identity, Youth and Crisis (London: Faber \& Faber, 1968), p. 22.

16 Axel Honneth, The Struggle for Recognition (Cambridge: Polity Press, 1995), pp. 118-123.

17 Véase G.H. Mead, Mind, Self, \& Society, p. 175.

18 Axel Honneth, The Struggle for Recognition, p. 138.

19 Véase Carlos García-Gual, "La visión de los otros en la antiguedad clásica" en M. León-Portilla et al., (ed) De Palabra y Obra en el Nuevo Mundo (Madrid: Siglo XXI, 1992), Vol. I, pp. 7-19.

20 Véase, Miguel León-Portilla, "Imágenes de los otros en Mesoamérica antes del encuentro", ibid., pp. 36-41.

21 Véase sobre esto Renato Ortiz, Um Outro Território, Ensaios sobre a mundialização (Sao Paulo: Olho d'Agua, s/f), p. 70.

22 C. Kluckhohn, Culture and Behaviour (New York: The Free Press of Glencoe, 1962), p. 214.

23 Maritza Montero, Ideología, Alienación e Identidad Nacional, Una aproximación psicosocial al ser venezolano (Caracas: Universidad Central de Venezuela, 1987), pp. 133-134.

24 D.M. Leite, 0 Caráter Nacional Brasileiro (Sao Paulo: Livraria Pioneira, 1969). Quoted in R. Ortiz, Um Outro Território, p. 71.

25 Francisco Antonio Encina, Nuestra Inferioridad Económica (Santiago: Editorial Universitaria, 1986), p. 178.

26 Hernán Godoy, El Carácter Chileno (Santiago: Editorial Universitaria, 1976), pp. 505-518.

27 B. Anderson, Imagined Communities (London: Verso, 1983).
28 Ibid., p. 15.

29 Véase R. Johnson, "Towards a Cultural Theory of the Nation: A British-Dutch Dialogue", en A. Galema et al., Images of the Nation (Amsterdam: Rodopi, 1993), pp. 191-194.

30 Ibid., p. 192.

31 Ibid., pp. 180-190.

32 J. Habermas, "The Limits of Neo-Historicism", Entrevista con J.M. Ferry en J. Habermas, Autonomy and Solidarity (London: Verso, 1992), p. 243.

33 J. Habermas, "Historical Consciousness and PostTraditional Identity: The Federal Republic's Orientation to the West", en J. Habermas, The New Conservatism (Cambridge, Mass.: MIT Press, 1989), p. 263.

34 Una posición abierta de este tipo puede verse en al análisis de la identidad mexicana realizado por Héctor Aguilar Camín, "La invención de México: Notas sobre nacionalismo e identidad nacional", Estudios Públicos, $\mathrm{N}^{\circ}$ 55 (invierno 1994), pp. 5-29. 